\title{
Quality of Life in Rural Areas of Moradabad district: A Block- wise Study
}

\author{
Dr. Fatma Mehar Sultana ${ }^{1}$, Zaid Alam ${ }^{2}$ \\ ${ }^{\prime}$ Assistant Professor (Women's College, Aligarh Muslim University, Aligarh, India) \\ ${ }^{2}$ Research Scholar (Department of Geography, Aligarh Muslim University, Aligarh, India)
}

\begin{abstract}
The present paper attempts to examine the quality of life in rural areas of Moradabad district and also analyse the block-wise spatial variation. The study is based on secondary source of data taken from the district handbook of Moradabad, 2011. For methodological purpose Z- Score technique has been applied and cartographical representations have been made through ArcView (3.2) in order to show the level of availability of amenities like education, medical facilities, drinking water, bank services and power supply. On the basis of Composite score value of these five amenities, we measured the quality of life of the different blocks of the district. The results from the study shows that three blocks namely, Moradabad, Bhagatpur Tanda and Kundarki Dingpur represent the region of high level of the quality of life. Nearly seventy percent of the blocks of the district come under medium category of quality of life, while, only one block has low level of quality of life.
\end{abstract}

Keywords: Quality of Life, Education, Power supply, medical facilities, drinking water, bank facilities and Moradabad District.

\section{INTRODUCTION}

According to census 2011 , about $70 \%$ population of the country belong to rural areas. Majority of India's rural population live with an insufficient social infrastructure and poor access to basic amenities like education, medical drinking water and electricity etc. Amenities are key to understanding quality of life because access to these basic amenities are crucial to rural development as they contribute to physical and material comfort.

The availability of services supplied in a rural area is able to influence local resident's quality of life (Layard 2005, Nussbaum and Sen 1993; Alkire, 2002, Prescott-Allen 2001, Ura et al 2004, Stiglitz, et al 2009). The individual quality of life does not depend on utilities of services available, but on functioning and capabilities (Sen, 1980; 1982; 1988). In general, the concept of quality of life has socio- economic dimensions and monetarist measurements embracing social and environmental features. Therefore, a large set of indicators must be premeditated and evaluated to take all of these features into account. However, as Boncinelli and Casini (2014) pointed out that the quality of life includes not only the identification of a set of indicators, but also their aggregation. The development of a region can be identified with an increase in the employment opportunities, availability of infrastructural facilities, amenities and services, proper distribution of resources, increase in production, and investment in consumption and so on (Sixl and Sixl,1999). Thus, the development refers to an improvement of all the sectors of economic, social and cultural pursuits (Verma, 1993). Availability of modern household amenities and assets also has dominant significance in the human life. It is also being realized that key dependencies exist between water supply and sanitation and improvement in the overall human development (Dreze and Murthi 2001; Gupta and Mitra 2002).It is unadventurously believed that housing conditions, availability of drinking water, sanitation facilities, etc. might contribute to the health improvement of the people and determine the quality of life of the society (Nayar, 1997).Other theoretical work by Roback $(1985,1988)$ and Blanchflower and Oswald (1996) show the relationship between amenities, quality of life, and rural economic growth.

\footnotetext{
Objective:

1. To analyze the current status of the district with respect to quality of life.

2. To find out the progress of development in Moradabad district.

3. To show the spatial variation in respect of quality of life.
}

\section{STUDY AREA}


Moradabad district is one of the districts of Uttar Pradesh state of India, and Moradabad city is the district headquarters. Moradabad is known for its export of brass handicraft to other countries, and is also thus called, "Brass City" or Peetal Nagri. Moradabad district extends from $28^{\circ} 20^{\prime}$ to $29^{\circ} 15^{\prime}$ North Latitudes and from $78^{\circ} 4^{\prime}$ to $79^{\circ}$ East Longitudes. It is bounded by tarai region of district Udham Singh Nagar and district Bijnor in the north, district Budaun in south, district Amroha in west and district Rampur in the east.

Figure-1: Locational Map of Moradabad

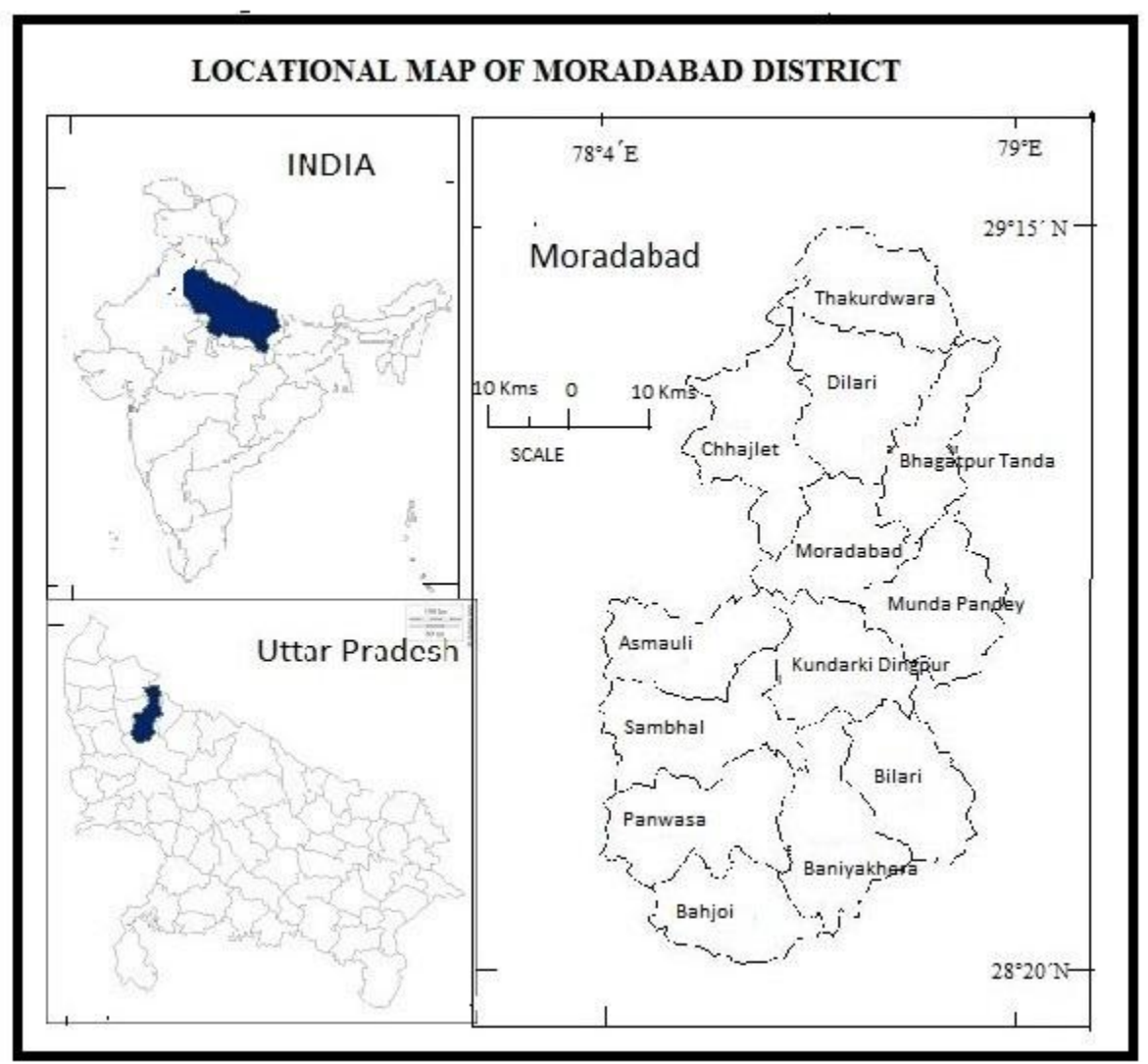

The average height of the district is $284 \mathrm{mt}$ above sea level. The total area of the district is $3,718 \mathrm{sq}$ Kms. According to census 2011, total population of Moradabad is 4,773,138. The whole district is divided into thirteen blocks. The economy of rural areas in Moradabad district is predominantly based on agriculture. Kharif and Rabi are the two principal harvests grown in the district. Wheat occupies the predominant place in terms of area and production. Sugarcane is the most important commercial crop in the district. Potato, tobacco, rice and barley are other main crops of the district.

\section{DATA BASE AND METHODOLOGY}

Present study is based on the secondary data taken from the District Census Handbook, Moradabad, 2011. The census provides data on percentage of rural population served by basic amenities like education, drinking water, bank and power supply facilities in Moradabad district at block level. In order to analyse the quality of life in rural areas of Moradabad district, we have taken five indicators like education, medical, drinking water, bank and power supply. The first attempts to transformation of data on individual variables into some kind of standard score using the method of Z-scores. Z-scores is a linear transformation of original data such that its mean becomes zero and its standard deviation becomes unity. It is denoted by $\mathrm{Z}$.

$$
Z_{i j}=\frac{X_{i j}-\overline{X_{i}}}{\sigma_{i}}
$$

Where, $Z_{i j}=$ Standardized value of the variable $i$ in District's block $j$.

$X_{i j}=$ Actual value of variable $i$ in district's block $j$.

$X_{i}=$ Mean value of variable $i$ in all block of the districts.

$\sigma_{i}=$ Standard deviation of variable $i$ in all block of the districts. 
In the second step, the z-scores of all variables have been added block wise and the average has been taken out for these variables which may be called as composite score (CS) for each block and may be algebraically expressed as:

$$
C S=\frac{\sum Z_{i j}}{N}
$$

Where, CS is composite score,

$\mathrm{N}$ refers to the number of indicators (variables).

The positive values relating to the $\mathrm{z}$-score of a block explain high level and negative values the low level of development in respect of amenities like education, medical, drinking water, bank and power supply. And quality of life is analysed through the composite scores of the blocks. Thus, the blocks of the district is divided into three categories, low ( -0.5 and below), medium ( -0.5 to 0.5$)$ and high (0.5 and above) on basis of its composite scores.

Besides, advanced cartographic techniques, GIS-Arc view programme (Version 3.2) have been applied to show the block wise variation in quality of life through map based on the important amenities in rural areas of Moradabad district.

\section{RESULTS AND DISCUSSION}

Table 1: Availability of basic amenities to the population in rural areas of Moradabad District, 2011

\begin{tabular}{|l|l|l|l|l|l|l|}
\hline S.N. & $\begin{array}{l}\text { Name of Community } \\
\text { Development Block }\end{array}$ & $\begin{array}{l}\text { Education } \\
(\mathbf{z}-\mathbf{s c o r e})\end{array}$ & $\begin{array}{l}\text { Medical } \\
(\mathbf{z}-\text {-score })\end{array}$ & $\begin{array}{l}\text { Banks } \\
(\mathbf{z} \text {-score) }\end{array}$ & $\begin{array}{l}\text { Power supply } \\
(\mathbf{z}-\text {-score) }\end{array}$ & $\begin{array}{l}\text { Composite } \\
\text { Scores }\end{array}$ \\
\hline 1 & Moradabad & 0.62 & 0.77 & 2.12 & 0.57 & 1.02 \\
\hline 2 & Bhagatpur Tanda & -0.75 & 0.91 & 1.18 & 1.00 & 0.58 \\
\hline 3 & Kundarki Dingpur & 0.08 & 1.27 & -0.14 & 1.00 & 0.55 \\
\hline 4 & Bilari & 1.22 & -0.09 & -0.33 & 0.92 & 0.43 \\
\hline 5 & Asmauli & 0.93 & 0.05 & -1.07 & 0.61 & 0.13 \\
\hline 6 & Bahjoi & 0.49 & -0.54 & -0.51 & 0.83 & 0.07 \\
\hline 7 & Baniyakhera & 0.20 & 0.64 & -1.23 & 0.30 & -0.02 \\
\hline 8 & Panwasa & 0.80 & -0.88 & 0.00 & -0.13 & -0.05 \\
\hline 9 & Thakurdwara & -0.52 & -0.66 & 0.87 & -0.04 & -0.09 \\
\hline 10 & Dilari & -1.81 & -0.04 & 0.73 & 0.75 & -0.09 \\
\hline 11 & Munda Pandey & 0.65 & 0.11 & 0.06 & -1.77 & -0.24 \\
\hline 12 & Sambhal & 0.04 & 0.93 & -1.26 & -1.01 & -0.33 \\
\hline 13 & Chhajlet & -1.98 & -2.49 & -0.42 & -1.74 & -1.66 \\
\hline
\end{tabular}

Source: Data through District Handbook, 2011.

\section{Education:}

Education is one of the basic means for improving quality of life. The overall education facility available to the people of Moradabad has been shown in the fig.2, among the thirteen blocks. Bilari, Asmauli, Panwasa, Munda Pandey and Moradabad fall under the category of high (above $0.500 \mathrm{z}$-score) availability of education facility three blocks form a contiguous region in the interior part of the district And Thakurdwara and Bhagatpur Tanda, Dilari and Chhajlet blocks, comes under the categories of low (below $-0.5 \mathrm{z}$-score) availability of education. These four blocks also form a contiguous region in the northern part of the district. Thus, the northern Part of the district represents the low availability of educational facilities. Though, these blocks is situated near the Moradabad block, where education facilities are highly developed, but these blocks have low availability of educational facilities. And rest blocks of the district, Bahjoi, Baniyakhera, Kundarki Dingpur and Sambhal have medium ( -0.5 to $0.5 \mathrm{z}$-score) availability of education facility. 
Fig. 2: Availability of Educational facilities

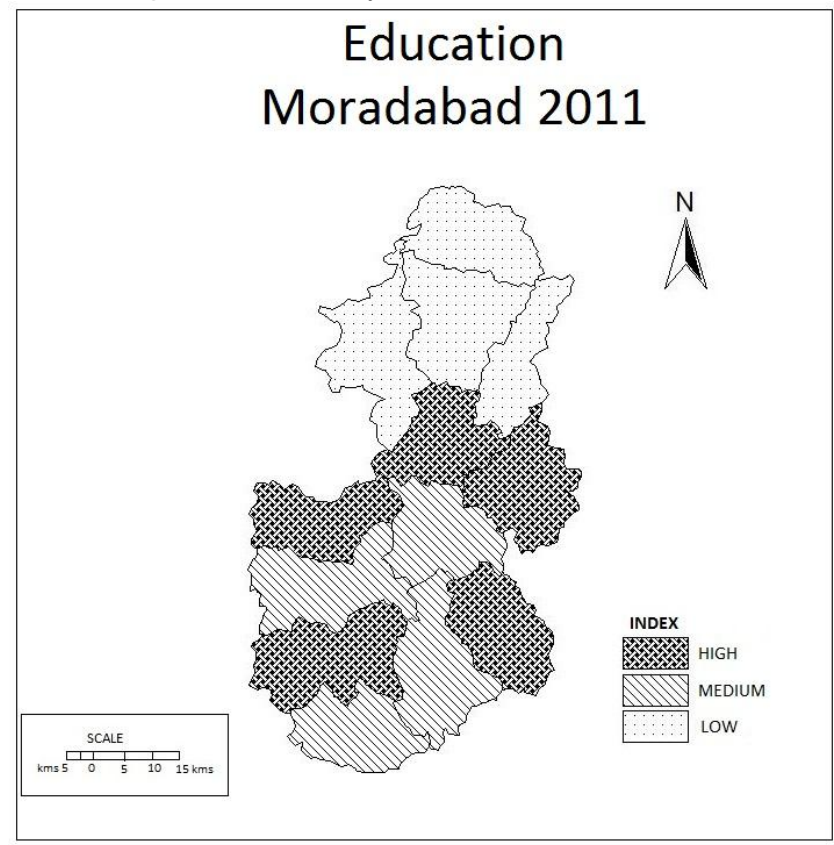

\section{Medical Facilities:}

Medical Facility is also one of the most important amenity for better quality of life. In generally we use a term 'health is wealth' means that if you have health, wealth will find its way towards you. Figure-3 shows spatial variation of medical facilities in rural areas of 13 blocks. Kundarki Dingpur, Sambhal and Bhagatpur Tanda, Moradabad and Baniyakhera blocks belong to the high (above $0.5 \mathrm{z}$-score) accessibility of medical facilities. These blocks are combined and form a region from north east to south west in district.

Fig. 3: Availability of Medical Facilities in Moradabad

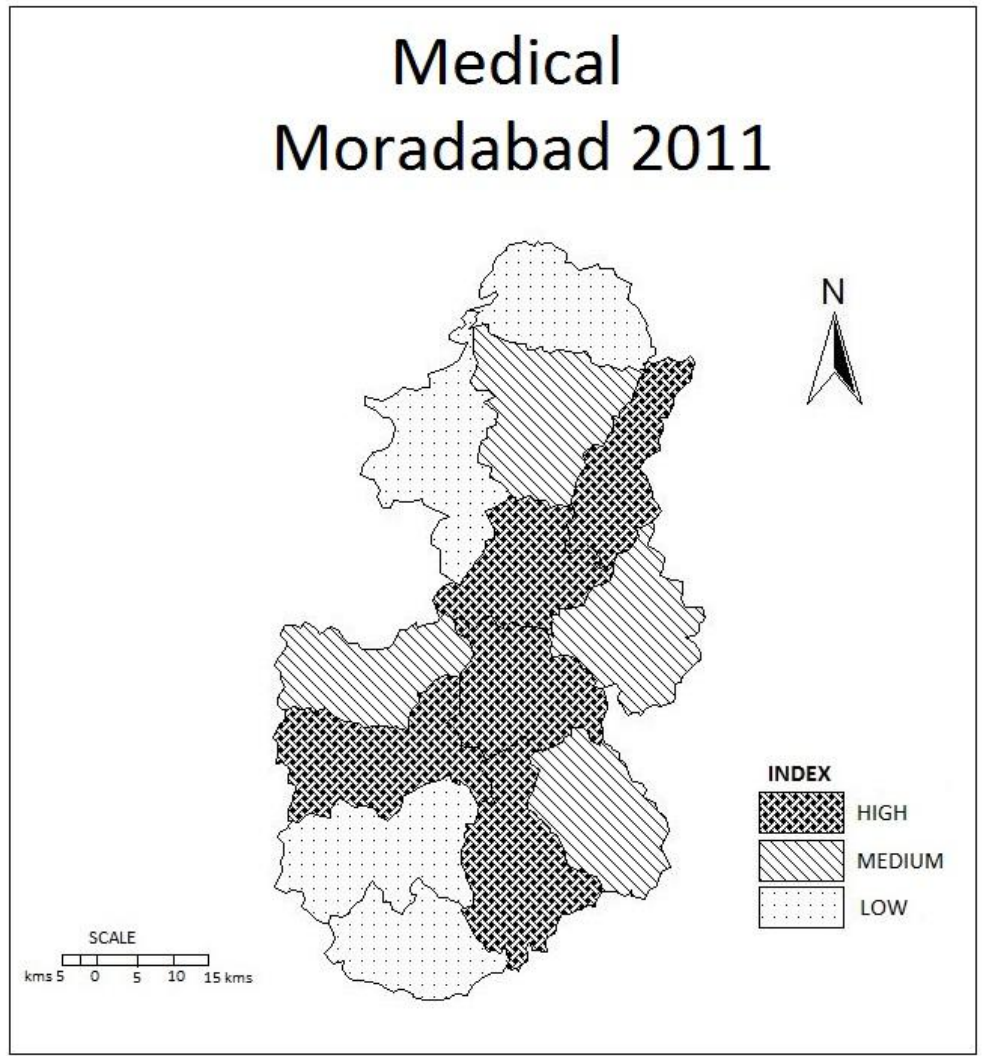


And four block, Munda Pandey, Asmauli, Dilari, Bilari comes under the group of medium (-0.5 to 0.5 z-score) availability of medical facilities. The rest three blocks, Bahjoi, Thakurdwara, Panwasa and Chhajlet, fall under the category of low (below -0.5) availability of medical facilities. These blocks cover the outer region of the district in both northern and southern part.

\section{Drinking Water:}

Water is necessary human need and thus the availability of drinking water is one of the basic amenity for every region. The every blocks of the district show the 100 percent availability of drinking water.

\section{Banks:}

Bank facility accessible to the population of Moradabad has been presented in fig. 4 among 13 blocks. Moradabad, Bhagatpur Tanda, Thakurdwara and Dilari bocks of the district represent the category of high (above $0.5 \mathrm{z}$-score value) availability of banks services and form a contiguous region in the northern part of the district. Five blocks of the district like Munda Pandey, Panwasa, Kundarki Dingpur, Bilari and Chhajlet comes under the category of medium ( -0.5 to $+0.5 \mathrm{z}$-score value) availability of bank facility. The rest of the blocks of the district, Bahjoi, Asmauli, Baniyakhera and Sambhal fall under the category of low (below -0.5) availability of bank facility. Thus, most of the area of northern part of the district represents high availability of bank facility. But the southern part of the district represent the category of medium and low availability of banks facility.

Fig. 4: Availability of Banks Facilities in Moradabad District

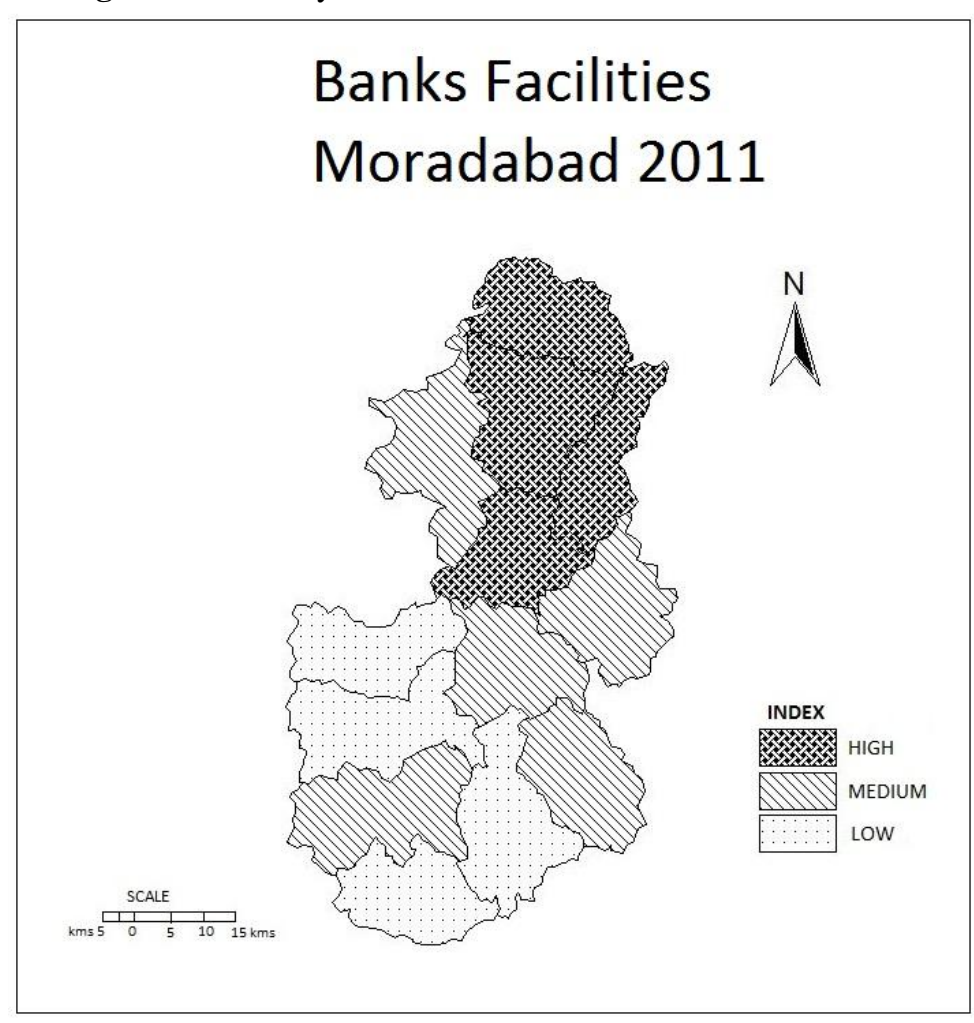

\section{Power Supply:}

Accessibility of power supply to rural population of Moradabad district at block level has been shown in fig.5. This figure present that Kundarki Dingpur, Bhagatpur Tanda, Bilari Bahjoi, Dilari, Asmauli and Moradabad blocks belong to the category of high (above 0.5) accessibility of Power supply in a district and form a contiguous region. And blocks like Baniyakhera Thakurdwara and Panwasa comes under the group of medium (-0.5 to 0.5) availability of Power Supply. And Sambhal Chhajlet and Munda padey falls under the category of low (below -0.5) accessibility of power supply. Thus the most of the area of Moradabad represents the high availability of power supply. 
Fig. 5: Availability of power supply in Moradabad district

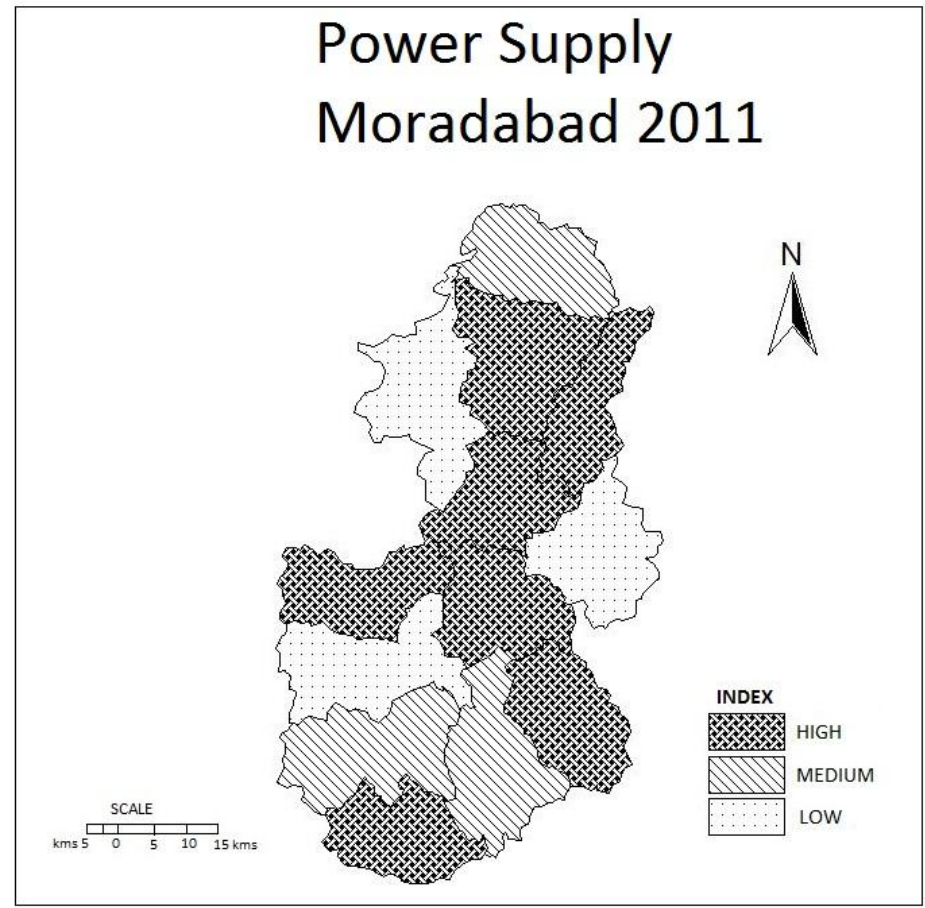

\section{Quality of life:}

Level of Quality of life in rural areas of Moradabad district among thirteen district is given in fig-5. This figure represents that rural population of Moradabad, Bhagatpur Tanda and Kundarki Dingpur blocks has high level (above 0.5 composite score value) of quality of life. These blocks form a contiguous region from north east to centre part of the district. Majority of the blocks like Bilari, Asmauli, Bahjoi Baniyakhera, Panwasa, Thakurdwara, and Dilari. Munda Pandey and Sambhal comes under the medium level of quality of life and these block cover the two third part of the district. And only one block, Chhajlet, represent the low level of quality of life. This block located in the north east of the district.

FIG.5: Quality of Life in Moradabad District

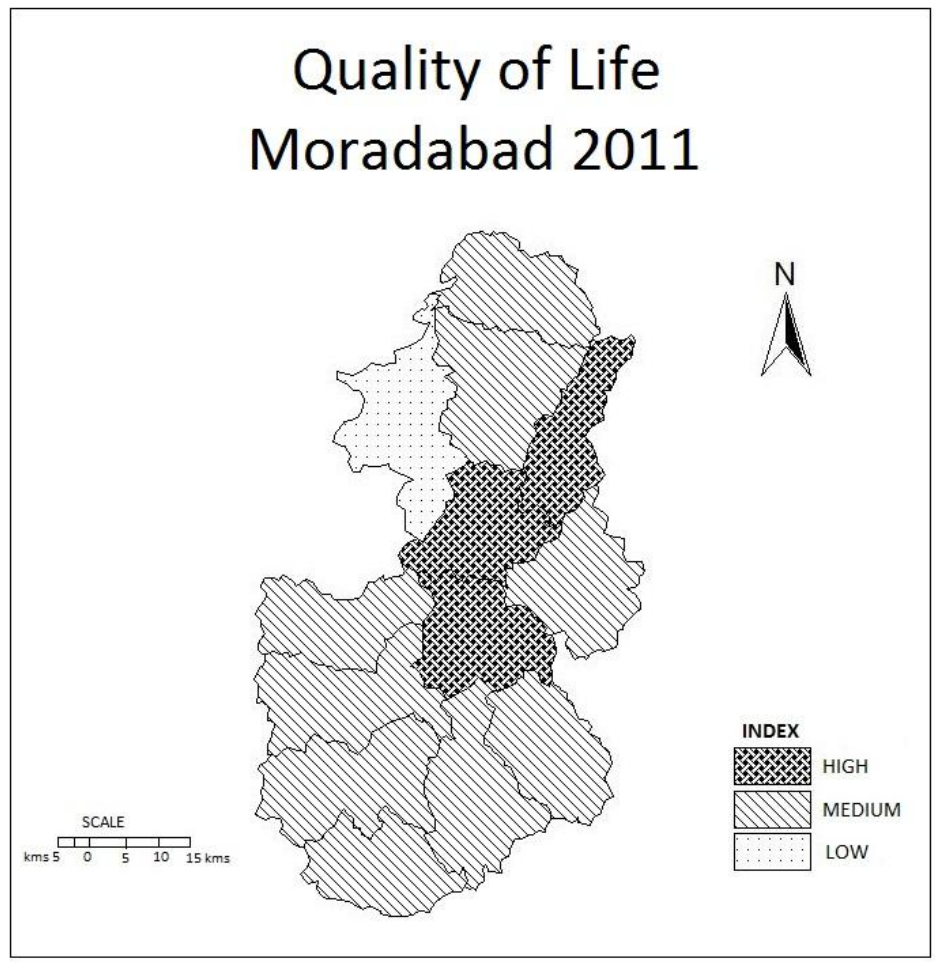




\section{CONCLUSION AND SUGGESTIONS}

The analyses of the study reveals that the blocks, Bilari, Asmauli, Panwasa, Munda Pandey and Moradabad belong to the category of high availability of educational facilities followed by Bahjoi, Baniyakhera, Kundarki Dingpur, Sambhal have medium and Thakurdwara, Bhagatpur Tanda, Dilari, Chhajlet blocks in the class of low category. In addition to it, the Kundarki Dingpur, Sambhal, Bhagatpur Tanda, Moradabad and Baniyakhera blocks fall under the category of high accessibility of medical facilities, while, Bahjoi, Thakurdwara, Panwasa and Chhajlet comes under the set of low category. Further, the Moradabad, Bhagatpur Tanda, Thakurdwara and Dilari bocks of the district represent the category of high availability of banks services, whereas, Munda Pandey, Panwasa, Kundarki Dingpur, Bilari and Chhajlet comes under the class of medium and rest of the blocks of the district (Bahjoi, Asmauli, Baniyakhera and Sambhal) fall under the category of low. As well as, the Kundarki Dingpur, Bhagatpur Tanda, Bilari, Bahjoi, Dilari, Asmauli and Moradabad blocks belong to the group of high accessibility of Power supply in a district, although, Baniyakhera Thakurdwara and Panwasa comes under the assemblage of medium in addition to the Sambhal Chhajlet and Munda Pandey falls under the category of low. In the last, the Moradabad, Bhagatpur Tanda and Kundarki Dingpur blocks has high level in the quality of life while, Bilari, Asmauli, Bahjoi Baniyakhera, Panwasa, Thakurdwara, Dilari, Munda Pandey, Sambhal comes under the medium and Chhajlet in the low category.

Thus after analysis we find out that the blocks having high availability of amenities as well as high level of quality of life form a contiguous region, as in the same manner the blocks comes under low availability of amenities and low level of quality of life, formed the contiguous zone. The northern part of the district having low availability of educational facilities but the availability of banks services are high in this region. About two third part of the district comes under the category of medium level of educational facilities and one fourth part of the district falls under the category of high level of quality of life. In order to improve the quality of life in terms of basic amenities like education, medical facilities, electricity, banking services the blocks with medium and low level of availability of these services should be taken care with special attentions.

\section{REFERENCES}

[1]. Alkire, S. (2005), 'Why the Capability Approach? Journal of Human Development, Vol. 6 (1). Pp. 115133.

[2]. Boncinelli, F. \& Casini, L. (2014), A Comparison of the Well-Being of Agricultural and Non Agricultural Households Using a Multicriterial Approach, Social Indicators Research, pp.183-195.

[3]. Blanchflower, D.G. \& Oswald, A.J. (1996), The Wage Curve, Cambridge MA: MIT Press.

[4]. District Census Handbook of Moradabad, 2011, Directorate of census operation, Uttar Pradesh,

[5]. Dreze, I. and Murthi, M. (2001). Fertility, education and development: evidence from India. Population and Development Review, Vol. 27, No.1, pp. 33-63.

[6]. Gupta, I. and Mitra, A. (2002). Basic amenities and health in urban India. National Medical Journal of India, Vol.15, No. 4, pp. 242-244.

[7]. Layard, R. (2005), Happiness: A Lesson from a New Science, Penguin Press,

[8]. Mukherjee, R. (1989), The Qualities of Life, Valuation in Social Research, Sage Publication, New Delhi.

[9]. Nayar, K.R. (1997). Housing Amenities and Health Improvement, Economic and Political Weekly, Vol. 32, No, 22, p. 1275.

[10]. Prescott-Allen, R., (2001). The Wellbeing of Nations. A Country-by-country Index of Quality of Life and the Environment. Island Press, Washington.

[11]. Porell, F.W. "Inter metropolitan Migration and Quality of Life.” J. Regl. Sci. 22(May 1982): 137-58.

[12]. Roback, J. (1985), Wages, Rents, and the Quality of Life, Journal of Political and Economy. pp. 125777. .

[13]. Roback, J. (1988), Wages, Rents, and Amenities: Differences among Workers and Regions, Economic Inquiry, pp. 23-41.

[14]. Rudzitis, G. (1999), Amenities Increasingly Draw People to the Rural West, Rural Development Perspectives Journal, pp.23-28.

[15]. Sen, A. (1980). Equality of what. In S. M. McMurrin (Eds.), the tanner lectures on human value). Salt Lake City: University of Utah Press, pp.195-220.

[16]. Sen, A. (1982). Choice, welfare, and measurement. Oxford, UK: Basil Blackwell.

[17]. Sen, A. K. (1988). The concept of development. In H. Chenery \& T. N. Srinivasan (Eds.), Handbooks of Development Economics. North-Holland: Elsevier Science Publishers.

[18]. Sen, A. (1993), 'Capability and Well-being' in Nussbaum and Sen, A. (eds), The quality of life, Oxford: Clarendon Press, pp. 30-53.

[19]. Sixl,W. and Sixl, K. (199), Quality of water quality of life. Central European Journal of Public Health, vol. 7(4), pp. 216-20. 
[20]. Smith, D.M. (1973), The Geograpohy of Social Well-being in the United States, McGraw-Hill Book Company, New York.

[21]. Stiglitz, J. et al. (2009). Report by the Commission on the Measurement of Economic Performance and Social Progress. 